\begin{tabular}{|c|c|}
\hline \multirow{3}{*}{ 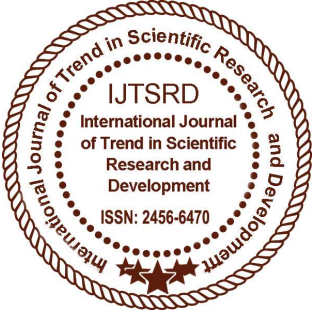 } & $\begin{array}{l}\text { International Journal of Trend in Scientific } \\
\text { Research and Development (IJTSRD) }\end{array}$ \\
\hline & International Open Access Journal \\
\hline & ISSN No: 2456 - 6470 | www.ijtsrd.com | Volume - 2 | Issue - 4 \\
\hline
\end{tabular}

\title{
Comprehensive investigation of Poly (methyl methacrylate) (PMMA) polymer for weathering with the combination of different blends of UV Stabilizers and Antioxidant
}

\author{
B. V. Shamsundara ${ }^{1}$, Dr. T. N. Shidhar ${ }^{2}$, Dr. S A Mohan Krishna ${ }^{3}$ \\ ${ }^{1}$ General Manager, The Automotive Research Association of India, Pune, Maharashtra, India \\ ${ }^{2}$ Professor, The National Institute of Engineering, Department of Mechanical Engineer, Mysore, Karnataka \\ ${ }^{3}$ Associate Professor, Vidyavardhaka College of Engineering, Mysore, Karnataka, India
}

\subsection{ABSTRACT}

Plastics (polymers) are nowadays clearly a material of choice in all the application sectors including in Automobile sector. Automotive manufacturer have relied on new technology for vehicular accessories which are all made-up of different polymers. Although these components offer an impressive range of attractive properties, the effect of climatic conditions on the durability and performance of these materials is not fully understood. The degradation/ variation of the mechanical properties of the specimen treated at different environmental/ atmospheric conditions are a primary concern when recommending such a composite for particular use. Generally when these components are subjected to weathering effects, they are prone to underperform. Therefore to improve their properties over time, different kinds of UV stabilizers, Hindered amine light stabilizer (HALS) and Antioxidant are used. However there is a need to study which UV stabilizers is to be used for the automobile applications polymers and what are its percentages? In this context, it is proposed to carry out a comprehensive investigation on degradation due to weathering of PMMA polymer with the combination of different percentages of UV stabilizers and antioxidant. This paper briefly examines the effects of the weathering on the performance and properties of PMMA polymer which is most commonly used materials in automobile sector. The use of accelerated weathering techniques to assist in assessing the durability of these product materials is also briefly discussed. The results after weathering and mechanical tests were discussed and optimized the percentage of blends as per the application.

\subsection{INTRODUCTION}

The motor vehicle industries are one of the major pioneer activities for social and economic progress of any country. Accordingly utilization of new technologies in different fields such as safety, reliability, comforts and environmental controls have to be considered as a paramount importance. Plastics are nowadays clearly a material of choice in all application sectors. The relative growth of plastics in the last three decades compared to other materials has been phenomenal and the automotive industry has been no exception in contributing to this growth. End users always expects high performance vehicles with greater comfort, safety, fuel efficiency but lower prices. At the same time society as a whole expects lower pollution levels and increased recovery of cars at the end of life. To meet theses demands, plastics having unique combination of properties to provide technological innovation with cost efficiency and sustainability [1].

Many components used in automobile applications are made of different types of polymers like, acrylonitrilebutadiene-styrene (ABS), Polycarbonates, Poly methyl methacrylate (PMMA), Acrylic, glass, resin etc. Although these materials offer an impressive range of attractive properties such as functionality, light weight, safety, resource efficiency, integrated system, economics, recyclables, resistance to environmental impacts, high strength, etc, the effect 
of climatic conditions on the durability and performance of these accessories are not fully understood. The reason may be longer duration simulation to environmental, high cost, etc. The durability, performance and rate of deterioration of these products are all significantly influenced by both the material composition, as well as the climatic conditions to which they are exposed and finally affect the aesthetics and safety of the vehicle. Consumers spend more money to maintain products that inevitably degrade and to replace products that fail. Thus, weathering is a major concern for manufacturing industries. Materials that fail as a result of exposure to outdoor environments accounts for a significant portion of this total cost [2].

The increase outdoor use of plastics in automobile has created a need for a better understanding of the effect of the environmental on these materials. The severity of damage depends largely on factors such as the nature of the environment, geographic location, type of polymeric material, and duration of exposure. The effect can be any where from a loss of colour or a slight crazing and cracking to a complete break down of a polymer structure. Any attempt to design plastic parts without a clear understanding of the degradation mechanisms induced by the environment would result in a premature failure of the product. [2].

Generally when these components are subjected to weathering effects, they are prone to underperform. Therefore to improve their properties over time, different kinds of UV stabilizers, Hindered amine light stabilizer (HALS) and Antioxidant are used. The protection given by stabilizers is essentially based on the absorption of harmful UV rays and the conversion into heat energy without damaging the substrate. However there is a need to study which UV stabilizers is to be used for the automobile applications polymers and what are its percentages? The stabilizers are designed to either inhibit or delay degradative changes rather than to stabilize properties.

\subsection{LITERATURE SURVEY}

Literature survey indicates that; available studies are mainly concentrating general applications of plastics, property of material, and a very limited study on effect of weathering [3-6]. Little studies are conducted to find out the material property change due exposure to climatic conditions. None of the studies directly involved to find out the automobile components degradation which are exposed to different atmospheric conditions and its effect on the automotive safety.

Several SAE papers details the importance of weathering data/cycle between geographical regions and requirements of country specific data, accelerated environmental degradation methods used at Lamborghini have been described and criteria for composite system selection for exterior applications reviewed, evaluated for exterior weathering in an attempt to improve the specifications for exterior mold-in-color plastics to meet five year durability for a 95th percentile sunbelt customer [7-9].

Many journals also details the different studies and outcome of the same on different types of polymers which includes the type of polymers, weathering cycle, property changes and correlations. [10-15].

Different patents explains regarding the polymer blends with different types of additives and also optimized for a particular use [16-18]. Similarly many regulations / standards refer the requirements of energy absorbing material requirements during vehicular crash / impact [21-23]. Many regulations and standards are available to evaluate these components performance as mandatory requirements before launch of the vehicle by respective manufacturer. These components need to meet the performance requirements as per national / international regulations not only when they are new but under different environmental conditions and even after exposure to such conditions for long duration [24-31]. National and international standards defines the weathering test requirements which includes the test procedure, light sources used for testing, duration, energy level to be applied along with temperature and humidity etc. [32-36]. Over and above, ASTM standard specifies the mechanical test such as tensile, elongation, impact, hardness procedure, sampling, test conditions etc. [37-40].

The above literature review indicates the possible prospects to carry out comprehensive further investigation on degradation of polymers used in automobile applications. Based on above, this investigation has been formulated as "Comprehensive investigation of Poly (methyl methacrylate) (PMMA) polymer for weathering with the combination of different blends of UV Stabilizers and Antioxidant". In this context, it is proposed to carry out a comprehensive investigation 
on degradation due to weathering of PMMA polymers with the combination of different percentages of UV stabilizers and antioxidant. In our study different UV stabilizers, and antioxidant in the range of $0.2 \%$ $1.0 \%$, and $0.2 \%$ respectively are used depending upon the substrate, intended functional life and sensitivity to UV degradation [16-18].

There are different types of failures expected in the polymers after weathering such as mechanical failure, thermal failure, Chemical failure and environmental failures. This study briefs mechanical characteristics failure after weathering exposure [3].

\subsection{ADDITIVES}

As indicated above, when PMMA polymers are subjected to weathering, they are prone to

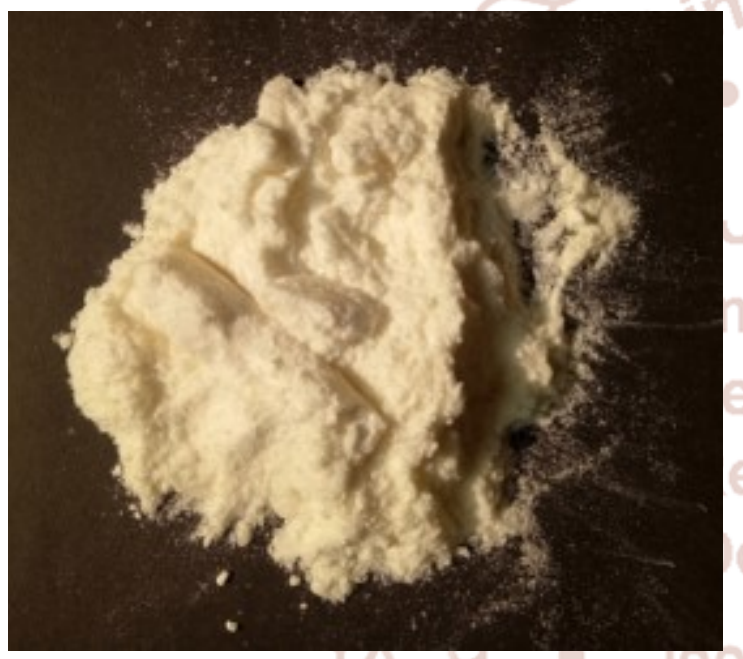

1). Benzoxazinone based UV light stabilizer: UV531 underperform. Therefore to improve their properties over time, different kinds of additives such as UV stabilizers and Antioxidant are used.

4.1 UV stabilizers are used frequently in plastics, including cosmetics and films. The primary function is to protect the substance from the long-term degradation effects from light, most frequently ultraviolet radiation. Different UV stabilizers are utilized depending upon the substrate, intended functional life, and sensitivity to UV degradation. Based on literature study, the following two type of UV stabilizers were used in this study. Figure 1 shows the Types of UV stabilizers used in the research

\section{Fig. 1 Types of UV Stabilizers Used}

4.2 Antioxidant substances are used to enhance the pro-ecological profile of the polymeric composites, enabling their use in products while complying with restrictive standards. The addition of antioxidant substances derived from flavonoids considerably improves the resistance of polymeric composites to ageing, especially under UV irradiation and climatic conditions with variable air humidity and solar radiation. The following two types of antioxidant were used with the ration of $3: 1$ in this study namely;

$>$ Primary Antioxidant 1010 [Tetrakis [methylene- $\beta$ (3,5-di-tert-butyl-4-hydroxyphenyl)propionate]methane]

$>$ Secondary Antioxidant 168 [Tris(2,4-ditertbutylphenyl)phosphite]
The Figure 2 shows the Type Antioxidant used in the study.

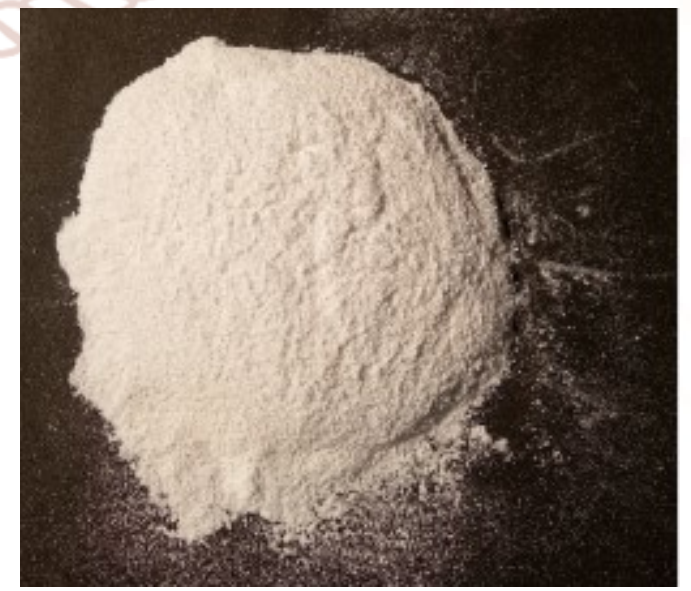

Primary Antioxidant 1010 and Secondary Antioxidant 168

Fig. 2 Types of Antioxidant 


\subsection{SAMPLE PREPARATION}

\subsection{General}

Different UV stabilizers and antioxidant in the range of $0.2 \%-1.0 \%$ and $0.2 \%$ respectively are used for intended functional life and sensitivity to UV degradation [16-18]. Table 1 shows the use of UV stabilizers and antioxidant with the different percentage of blends in PMMA.

\begin{tabular}{|c|c|c|c|c|c|c|}
\hline Sr. & Name of Components & Type & \multicolumn{4}{|c|}{$\%$ wt } \\
\hline \multicolumn{3}{|c|}{ Sample designation } & $\mathbf{P A}$ & PB & $\mathbf{P C}$ & PD \\
\hline 1 & Polymer (thermoplastic) & $\begin{array}{l}\text { Poly(methyl methacrylate) } \\
\text { (PMMA) } \\
\left(\underline{\mathrm{C}}_{5} \underline{\mathrm{O}}_{2} \underline{\mathrm{H}}_{8}\right)_{n}\end{array}$ & $\begin{array}{l}100 \\
\%\end{array}$ & $\begin{array}{l}99.6 \\
\%\end{array}$ & $99.2 \%$ & $\begin{array}{c}98.8 \\
\%\end{array}$ \\
\hline 2 & $\begin{array}{l}\text { Benzoxazinone based } \\
\text { UV light stabilizer }\end{array}$ & $\begin{array}{l}\text { UV531 } \\
\text { [2-hydroxy-4- } \\
\text { octyloxybenzophenone] }\end{array}$ & 0 & $0.1 \%$ & $0.3 \%$ & $0.5 \%$ \\
\hline 3 & $\begin{array}{l}\text { Diphenyl acrylates based } \\
\text { UV light stabilizer }\end{array}$ & $\begin{array}{l}\text { UV335 } \\
\text { [ethyl-2-cyano-3,3- } \\
\text { diphenylacrylate] }\end{array}$ & 0 & $0.1 \%$ & $0.3 \%$ & $0.5 \%$ \\
\hline 4 & $\begin{array}{lr}\text { Antioxidant } & \text { primary } \\
\text { Antioxidant } & \text { secondary } \\
\text { (Mixture of } 3: 1 \text { ratio) }\end{array}$ & $\begin{array}{l}>\text { Primary Antioxidant } 1010 \\
\text { [Tetrakis [methylene- } \beta-(3,5 \text {-di- } \\
\text { tert-butyl-4-hydroxyphenyl)- } \\
\text { propionate]methane] } \\
>\text { Secondary Antioxidant } 168 \\
\text { [Tris(2,4-ditert- } \\
\text { butylphenyl)phosphite] }\end{array}$ & 0 & & $0.2 \%$ & \\
\hline
\end{tabular}

\section{Table 1: Different Percentage of Blends used in PMMA}

\subsection{Fabrication of blends}

PMMA test specimens along with UV stabilizers and antioxidant blends have been fabricated using Injection molding process. The PMMA materials were received in the granular form and all other additives are in the form of powder. These materials are mixed thoroughly as per the percentages as shown in Table1 above in room temperature. The PMMA test granules along with UV stabilizers and antioxidant were weighed using very high accuracy weighing machine as shown in the figure 3.

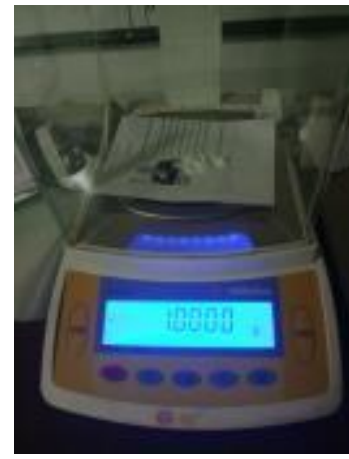

Measurement device of UV stabilizers and antioxidant

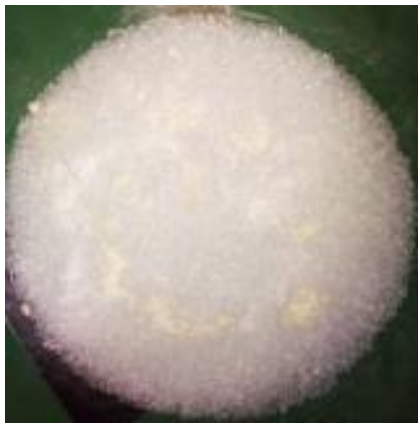

Preparation of PMMA blends

Fig. 3 Type of weighing machines and PMMA blends 
International Journal of Trend in Scientific Research and Development (IJTSRD) ISSN: 2456-6470

Then these blends are placed in the hopper of the injection moulding machine from which it is fed to a heated cylinder. Granules are heated in the cylinder to melt or plasticize at about $230^{\circ} \mathrm{C}$. The test specimens are prepared very accurately as per ASTM standards.

\subsection{Sampling}

The table 2 shows the No. of specimen calculation for the experimentations. Normally, the standard number of test specimens required by all ASTM standards [37-40] is at least five. Hence, fabricated the number of test specimens as per the ASTM standard with the combination of number of exposure and additives blends. The tests are conducted at the intervals of $1167 \mathrm{~kJ} / \mathrm{m}^{2}(865 \mathrm{~h}), 2333 \mathrm{~kJ} / \mathrm{m}^{2}(1730 \mathrm{~h})$, and $3500 \mathrm{~kJ} / \mathrm{m}^{2}(2596 \mathrm{~h})$ exposure of weathering.

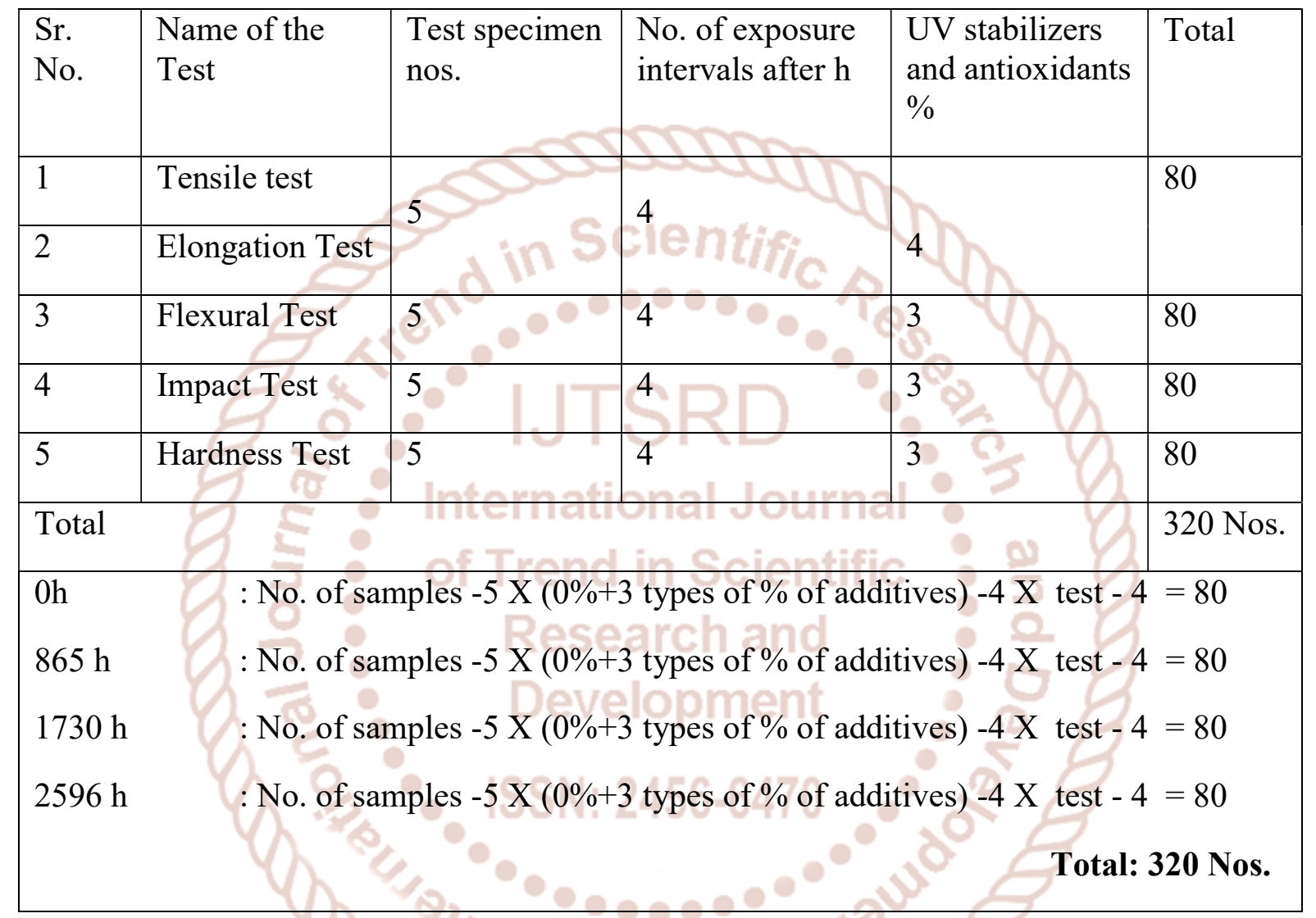

Table 2: No. of test specimen derived as per ASTM

The above samples were divided into 4 different lots as per the different combination of blends for the purpose of identification during experiments. Figure 4 shows the four lots of PMMA blends.

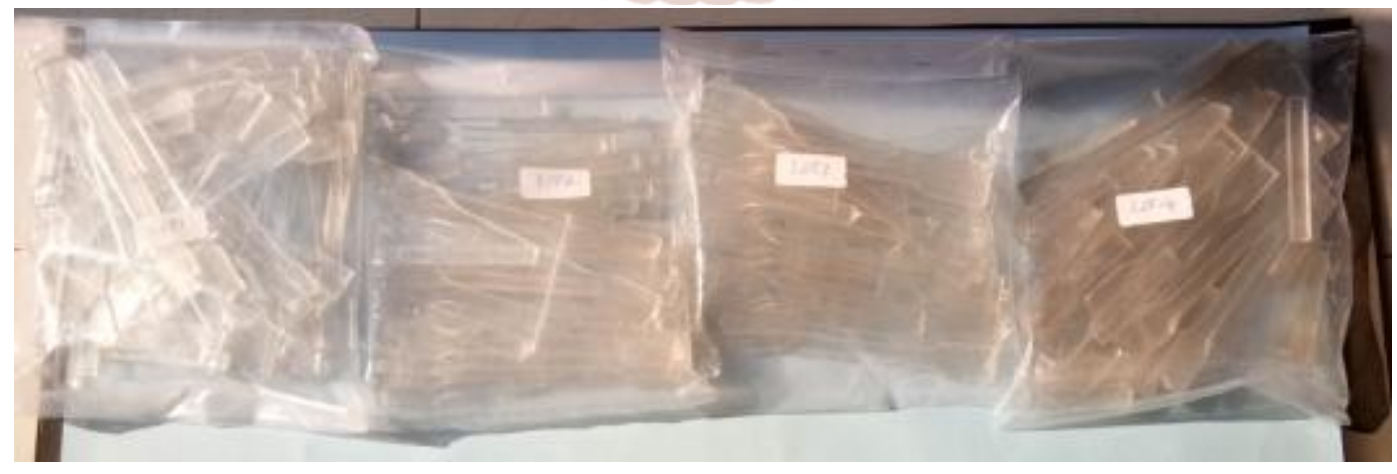

Fig. 4 Four lots of PMMA blends 
International Journal of Trend in Scientific Research and Development (IJTSRD) ISSN: 2456-6470

The definitions of lot, no. of samples required, tests and standard to be followed is explained in the Table 3 .

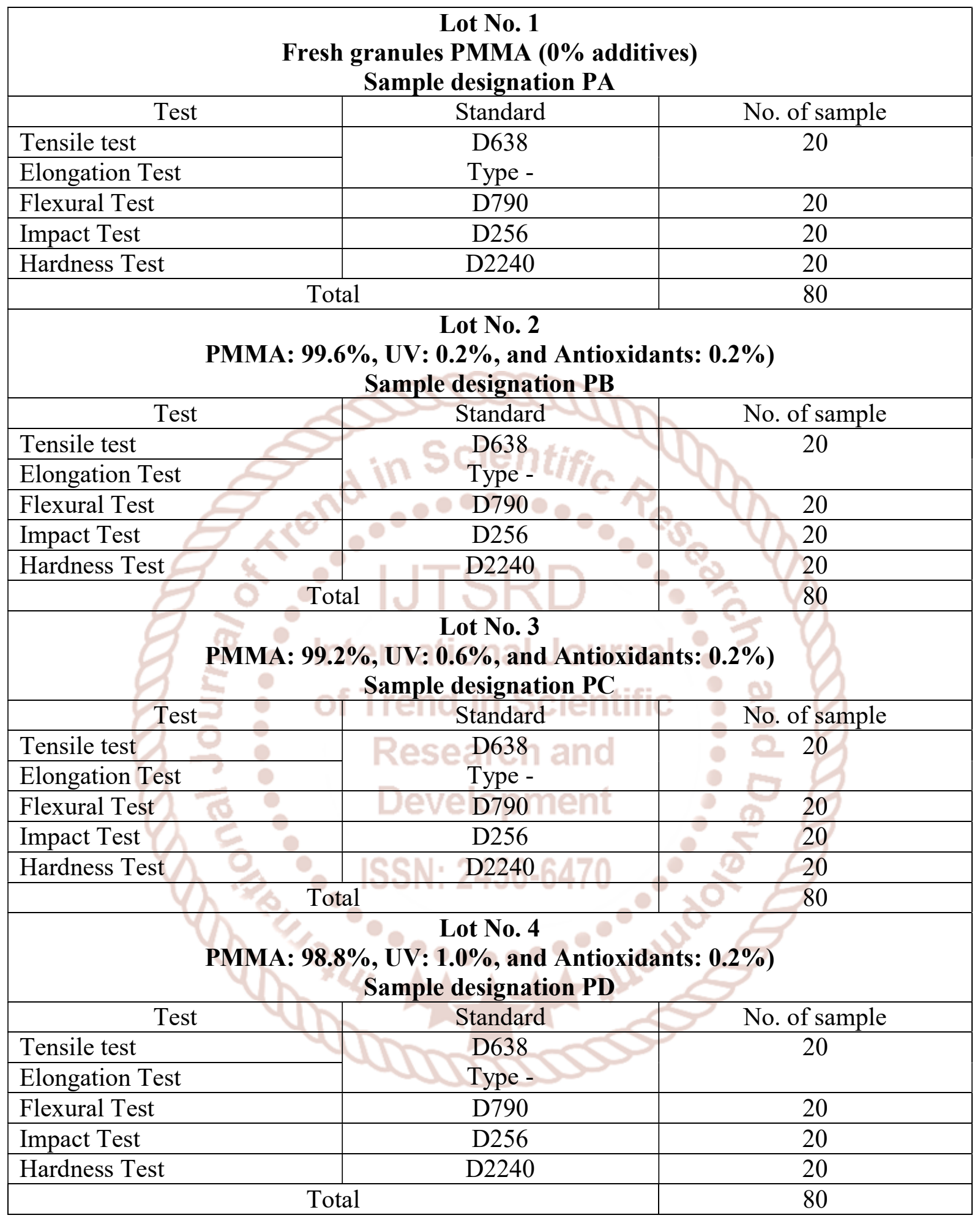

Table 3 Definitions of lot, no. of samples required, tests and standard to be followed for PMMA blends

\subsection{Conditioning of Samples:}

ASTM test specifications defines a conditioning period at $23^{\circ} \mathrm{C}$ and $50 \% \mathrm{RH}$ prior to testing to ensure that the test specimens are stabilized at the required test conditions and to provide consistency for material comparisons [37-40]. For the purpose of our study, a sophisticated state of the art temperature humidification control system was used that monitors the conditioning environment 48 hours to ensure the $23^{\circ} \mathrm{C}$ and $50 \% \mathrm{RH}$. This system used for the condition is ISO 17025 Accreditation. Figure 5 
International Journal of Trend in Scientific Research and Development (IJTSRD) ISSN: 2456-6470

shows the complete set of samples for the lot No.1 as an example for PMMA materials respectively. The same number of samples were prepared for all lots.

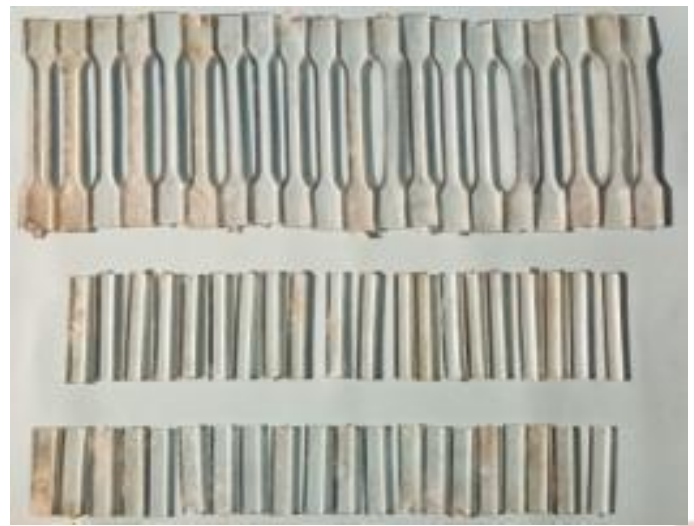

Fig. 5 The complete set of samples for the lot No.1 as an example

\subsection{EXPERIMENTAL INVESTIGATION OF MECHANICAL PROPERTIES OF PMMA POLYMERS}

\subsection{Experimentation}

As per the data collection and computed, the average Indian total $(295-3000 \mathrm{~nm})$ irradiance per year is $6437 \mathrm{MJ} / \mathrm{m}^{2}$. However for the purpose of experimentation as a worst case criteria western Indian total average irradiance per year was used which is equal to $6966 \mathrm{MJ} / \mathrm{m}^{2}$, which is equal to around $3500 \mathrm{~kJ} / \mathrm{m}^{2}$ for $0.55 \mathrm{~W} / \mathrm{m}^{2}$ at $340 \mathrm{~nm}$.

The test method is followed for this experiment is SAE J 1960 [34]. The equipment used for accelerating weathering is Atlas $\mathrm{Ci} 4000$. The layout of the equipment is shown in the Figure No. 6 and 7 as below [3].

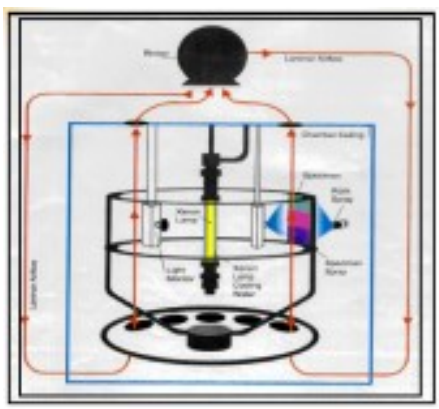

Figure 6. Layout of the water cooled $\mathrm{Ci}$ 4000 weather-Omete

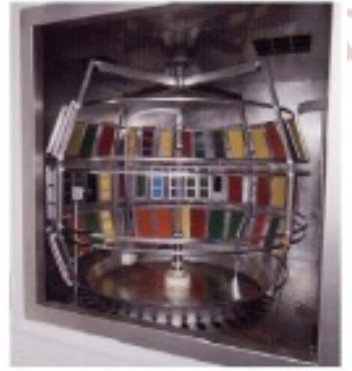

Figure 7. Layout of the samples in side the weather-Ometer

\subsection{Light source used for experiments}

The xenon long arc, when properly filtered, simulates UV and visible solar radiation more closely than any other artificial light source was used. The spectrum of xenon arc lamp versus day light over a range of 300 to $800 \mathrm{~nm}$ is shown in Figure 8. Xenon arc is a precision gas discharge lamp in a sealed quartz tube. The spectral power distribution is altered though filtering to simulate solar radiation. The weather-o-meter used in this experimentation is $\mathrm{Ci} 4000$ water cooled [4].

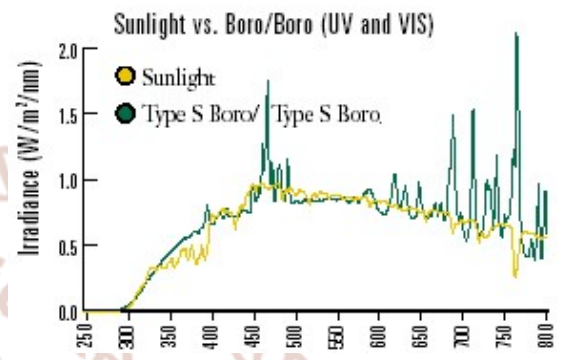

Figure 8. Spectrum of xenon arc lamp versus day light over a range of 300 to $800 \mathrm{~nm}$.

The tests are conducted at the intervals of 1167 $\mathrm{kJ} / \mathrm{m}^{2}(865 \mathrm{~h}), 2333 \mathrm{~kJ} / \mathrm{m}^{2}(1730 \mathrm{~h})$, and $3500 \mathrm{~kJ} / \mathrm{m}^{2}$ $(2596 \mathrm{~h})$ exposure of weathering. The detail calculation is also explained in appendix A.

\subsection{AI EXPERIMENTAL RESULTS \\ INVESTIGATION}

Table 4 shows the Indian weathering derived test cycle was followed for this experiments.

\begin{tabular}{|c|c|c|}
\hline Controls & $\begin{array}{l}\text { Dark } \\
\text { Cycle }\end{array}$ & Light Cycle \\
\hline $\begin{array}{l}\text { Automatic } \\
\text { irradiance }\end{array}$ & -- & $\begin{array}{l}0.55 \mathrm{~W} / \mathrm{m}^{2} \text { at } 340 \mathrm{~nm} \\
\pm 0.01 \mathrm{~W} \mathrm{~m} \mathrm{~m}^{2}\end{array}$ \\
\hline $\begin{array}{l}\text { Chamber } \\
\text { temperature }\end{array}$ & $\begin{array}{l}38^{\circ} \mathrm{C} \pm 2 \\
{ }^{\circ} \mathrm{C}\end{array}$ & Automatic \\
\hline Relative humidity & $\begin{array}{l}95 \% \pm \\
5 \%\end{array}$ & $50 \% \pm 5 \%$ \\
\hline $\begin{array}{l}\text { Total Radiant } \\
\text { exposure }\end{array}$ & $6966 \mathrm{MJ} / \mathrm{m}^{2}$ & \\
\hline
\end{tabular}

Table 4: Weathering Test cycle followed for experiments

The blended samples were tested as per the above ASTM standards for the Tensile test, Elongation Test, Flexural Test, Impact Test, Hardness Test. Each 
mechanical test was performed under similar temperature conditions of conditioning. The instruments referred above used to measure the material mechanical properties after exposure to different radiant energy along with all other weather conditions. The instruments used for this study are covered under ISO: 17025 / NABL accreditation. Typical samples photographs after each test as shown in figure 9.

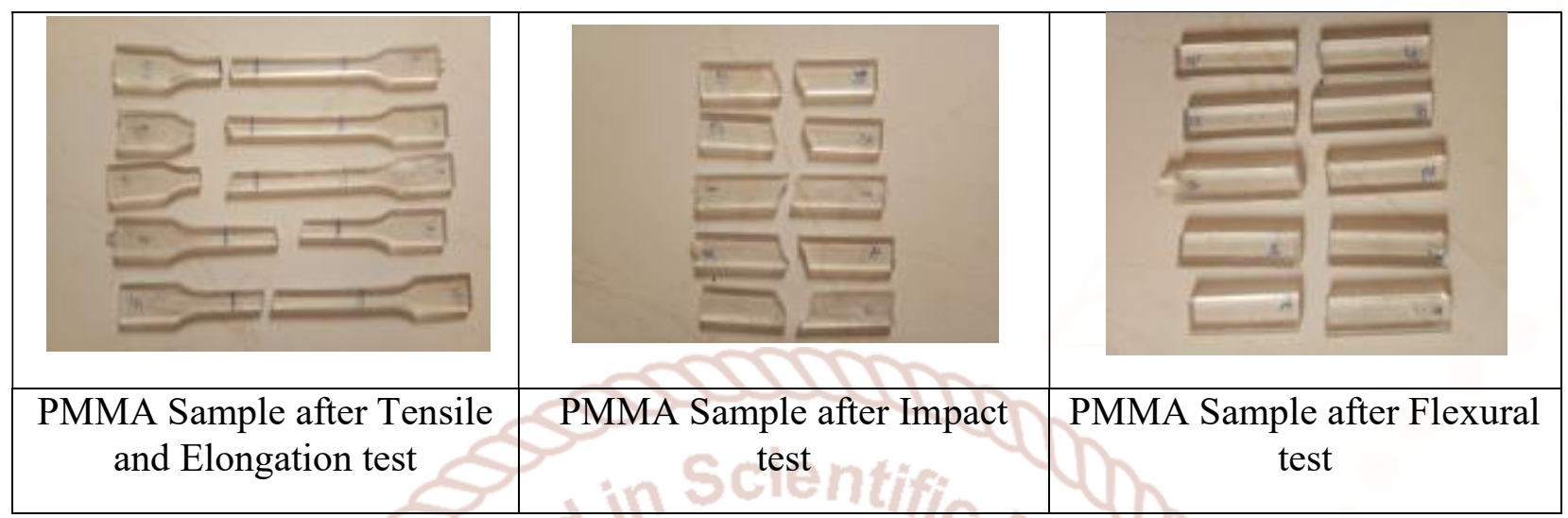

Fig. 9 Typical Sample photographs after each test

\subsection{Determination of Tensile Strength Test Results of PMMA}

Tensile strength retention during weathering was studied for the specimens categorized as PA, PB, PC and PD represents PMMA. Table 5 shows the average tensile strength test results of five PMMA polymer blend samples after intervals of $0 \mathrm{~h}, 1167 \mathrm{~kJ} / \mathrm{m}^{2}(865$ h), $2333 \mathrm{~kJ} / \mathrm{m}^{2}(1730 \mathrm{~h})$, and $3500 \mathrm{~kJ} / \mathrm{m}^{2}(2596 \mathrm{~h})$ radiant exposure to weathering.

Table 5. Overall Tensile Test Results after each radiant exposure of the PMMA bend samples

\begin{tabular}{|l|l|c|c|c|c|}
\hline $\begin{array}{l}\text { Sample } \\
\text { set No. }\end{array}$ & $\begin{array}{c}\text { Total } \\
\text { radiant } \\
\text { energy } \\
\end{array}$ & \multicolumn{4}{|c|}{$\begin{array}{l}\text { Average Tensile strength for } \\
\text { five sample (MPa) blends with }\end{array}$} \\
\cline { 3 - 6 } & & \multicolumn{4}{|c|}{ Samp stabilizers and Antioxidant } \\
\cline { 3 - 6 } & & $\boldsymbol{P A}$ & $\boldsymbol{P B}$ & $\boldsymbol{P C}$ & $\boldsymbol{P D}$ \\
\hline 1 & 0 & $\mathbf{5 9 . 9 7}$ & $\mathbf{5 9 . 6 8}$ & $\mathbf{6 0 . 3 7}$ & $\mathbf{6 0 . 6 3}$ \\
\hline 2 & 1167 & $\mathbf{5 7 . 0 9}$ & $\mathbf{5 8 . 1 2}$ & $\mathbf{6 1 . 2 5}$ & $\mathbf{5 7 . 9 2}$ \\
\hline 3 & 2333 & $\mathbf{5 3 . 1 0}$ & $\mathbf{5 6 . 3 4}$ & $\mathbf{6 0 . 3 3}$ & $\mathbf{5 4 . 3 2}$ \\
\hline 4 & 3500 & $\mathbf{4 4 . 1 9}$ & $\mathbf{4 7 . 6 4}$ & $\mathbf{5 5 . 0 6}$ & $\mathbf{4 8 . 0 0}$ \\
\hline
\end{tabular}

The Fig. 10 shows the overall trend of tensile strength with radiant exposure of PMMA material

\section{Tensile test Results - PMMA}

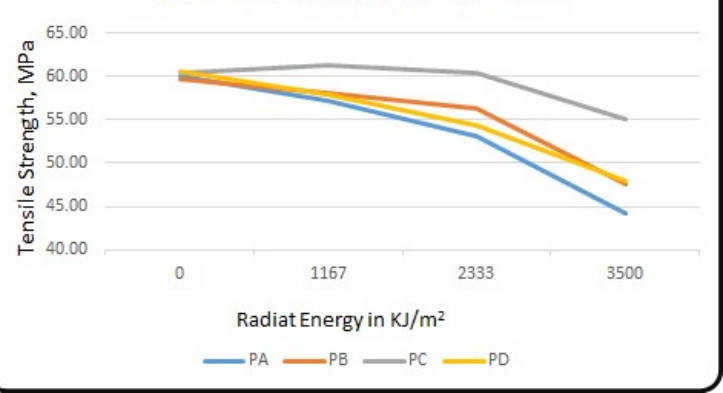

The Fig.10 shows the overall trend of tensile test with radiant exposure of PMMA material

The results shows that tensile strength of PMMA samples $\mathrm{PA}, \mathrm{PB}, \mathrm{PC}$ and $\mathrm{PD}$ starts decreases continuously for the exposure of $3500 \mathrm{~kJ} / \mathrm{m}^{2}$. The variation was observed for the PMMA samples PA, $\mathrm{PB}, \mathrm{PC}$ and PD are $26.3 \%, 20.2 \%, 8.8 \%$ and $20.8 \%$ respectively. The sample PA which is a fresh sample without any concentration of UV and antioxidant shows the maximum percentage of tensile strength decline as compared to with bends of UV and antioxidants. However the sample AC shows the less decline of tensile strength in the order of $8.8 \%$ as compared to other samples. This trend shows that the concentration of $0.6 \%$ blends with UV stabilizers and $0.2 \%$ of Antioxidant shows the better results for the tensile strength of PMMA as compared to other percentage of blends concentration.

\subsection{Determination of Elongation Test Results of PMMA}

Elongation property retention during weathering was studied for the specimens PA, PB, PC and PD. Table 
6 shows the average elongation retention test results of five PMMA polymer blend samples after intervals of $0 \mathrm{~h}, 1167 \mathrm{~kJ} / \mathrm{m}^{2}(865 \mathrm{~h}), 2333 \mathrm{~kJ} / \mathrm{m}^{2}(1730 \mathrm{~h})$, and $3500 \mathrm{~kJ} / \mathrm{m}^{2}(2596 \mathrm{~h})$ radiant exposure to weathering.

Table 6. Overall Elongation Test Results after each radiant exposure of the PMMA bend samples

\begin{tabular}{|c|c|c|c|c|c|}
\hline \multirow{2}{*}{$\begin{array}{c}\text { Sample } \\
\text { set No. }\end{array}$} & $\begin{array}{c}\text { Total } \\
\text { radiant } \\
\text { energy } \\
\mathrm{kJ} / \mathrm{m} 2\end{array}$ & \multicolumn{4}{|c|}{$\begin{array}{c}\text { Average elongation test for five } \\
\text { sample (MPa) blends with UV } \\
\text { stabilizers and Antioxidant }\end{array}$} \\
\cline { 3 - 6 } & & \multicolumn{4}{|c|}{ Sample designation } \\
\cline { 3 - 6 } & & $\boldsymbol{P A}$ & $\boldsymbol{P B}$ & $\boldsymbol{P C}$ & $\boldsymbol{P D}$ \\
\hline 1 & 0 & $\mathbf{1 0}$ & $\mathbf{1 0}$ & $\mathbf{1 0}$ & $\mathbf{1 0}$ \\
\hline 2 & 1167 & $\mathbf{8}$ & $\mathbf{9}$ & $\mathbf{7}$ & $\mathbf{7}$ \\
\hline 3 & 2333 & $\mathbf{7}$ & $\mathbf{7}$ & $\mathbf{8}$ & $\mathbf{6}$ \\
\hline 4 & 3500 & $\mathbf{5}$ & $\mathbf{7}$ & $\mathbf{9}$ & $\mathbf{6}$ \\
\hline
\end{tabular}

The Fig.11 shows the overall trend of elongation test with radiant exposure of PMMA material

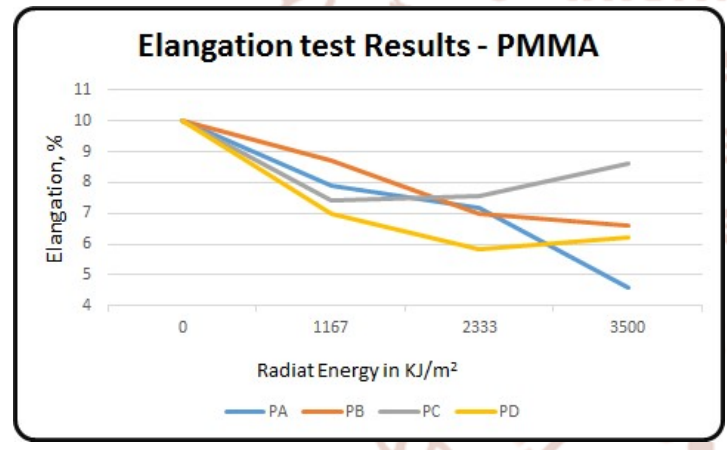

Fig.11 overall trend of elongation proprieties with radiant exposure of PMMA material

The results shows that Elongation properties of PMMA samples PA, PB, PC and PD starts decreases continuously for the exposure of $3500 \mathrm{~kJ} / \mathrm{m} 2$. . The variation was observed for the PMMA samples PA, $\mathrm{PB}, \mathrm{PC}$ and $\mathrm{PD}$ are $54.0 \%, 34.0 \%, 14.0 \%$ and $38.0 \%$ respectively. The sample PA which is a fresh sample without any concentration of UV and antioxidant shows the maximum percentage of Elongation properties decline as compared to with bends of UV and antioxidants. However the sample AC shows the less decline of Elongation properties in the order of $14.0 \%$ as compared to other samples. This trend shows that the concentration of $0.6 \%$ blends with UV stabilizers and $0.2 \%$ of Antioxidant shows the better results for the Elongation properties of PMMA as compared to other percentage of blends concentration.

\subsection{Determination of Flexural Strength Test Results of PMMA}

Flexural Strength retention during weathering was studied for the specimens PA, PB, PC and PD. Table 7 shows the average Flexural Strength retention test results of five PMMA polymer blend samples after intervals of $0 \mathrm{~h}, 1167 \mathrm{~kJ} / \mathrm{m}^{2}(865 \mathrm{~h}), 2333 \mathrm{~kJ} / \mathrm{m}^{2}(1730$ $\mathrm{h})$, and $3500 \mathrm{~kJ} / \mathrm{m}^{2}(2596 \mathrm{~h})$ radiant exposure to weathering.

\section{Table 7. Overall Flexural Strength Test Results after each radiant exposure of the PMMA bend} samples

\begin{tabular}{|c|c|c|c|c|c|}
\hline \multirow{3}{*}{\begin{tabular}{|c|} 
Sample \\
set No. \\
ntiffy
\end{tabular}} & \multirow{3}{*}{$\begin{array}{l}\text { Total } \\
\text { radiant } \\
\text { energy } \\
\mathrm{kJ} / \mathrm{m} 2\end{array}$} & \multicolumn{4}{|c|}{$\begin{array}{l}\text { Average Flexural strength for } \\
\text { five sample (MPa) blends with } \\
\text { UV stabilizers and Antioxidant }\end{array}$} \\
\hline & & \multicolumn{4}{|c|}{ Sample designation } \\
\hline & & $P A$ & $P B$ & $P C$ & $P D$ \\
\hline & 0 & 66.35 & 67.85 & 67.45 & 68.18 \\
\hline & 1167 & 66.03 & 67.65 & 67.51 & 68.14 \\
\hline & 2333 & 64.91 & 64.50 & 67.63 & 64.94 \\
\hline & 3500 & 58.09 & 60.18 & 65.76 & 60.09 \\
\hline
\end{tabular}

The Fig.12 shows the overall trend of Flexural strength with radiant exposure of PMMA material

Flextural Strength Results - PMMA

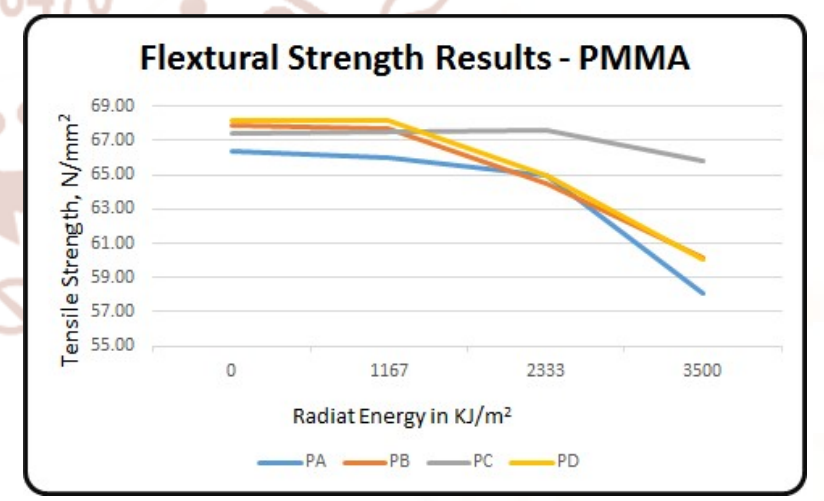

Fig.12 overall trend of flexural proprieties with radiant exposure of PMMA material

The results shows that Flexural strength of PMMA samples PA, PB, PC and PD starts decreases continuously for the exposure of $3500 \mathrm{~kJ} / \mathrm{m}^{2}$. The variation was observed for the PMMA samples PA, $\mathrm{PB}, \mathrm{PC}$ and $\mathrm{PD}$ are $12.54 \%, 11.31 \%, 2.50 \%$ and $11.87 \%$ respectively. The sample PA which is a fresh sample without any concentration of UV and antioxidant shows the maximum percentage of 
Flexural strength decline as compared to with bends of UV and antioxidants. However the sample AC shows the less decline of Flexural strength in the order of $2.5 \%$ as compared to other samples. This trend shows that the concentration of $0.6 \%$ blends with UV stabilizers and $0.2 \%$ of Antioxidant shows the better results for the Flexural strength of PMMA as compared to other percentage of blends concentration.

\subsection{Determination of Impact Strength Test Results of PMMA}

Impact strength retention during weathering was studied for the specimens PA, PB, PC and PD. Table 8 shows the average Impact strength retention test results of five PMMA polymer blend samples after intervals of $0 \mathrm{~h}, 1167 \mathrm{~kJ} / \mathrm{m}^{2}(865 \mathrm{~h}), 2333 \mathrm{~kJ} / \mathrm{m}^{2}(1730$ $\mathrm{h})$, and $3500 \mathrm{~kJ} / \mathrm{m}^{2}(2596 \mathrm{~h})$ radiant exposure to weathering.

Table 8. Overall Impact strength Test Results after each radiant exposure of the PMMA bend samples

\begin{tabular}{|c|c|c|c|c|c|}
\hline \multirow[t]{3}{*}{$\begin{array}{l}\text { Sample } \\
\text { set No. }\end{array}$} & \multirow{3}{*}{$\begin{array}{l}\text { Total } \\
\text { radiant } \\
\text { energy } \\
\mathrm{kJ} / \mathrm{m} 2\end{array}$} & \multicolumn{4}{|c|}{$\begin{array}{l}\text { Average Impact Test for five } \\
\text { sample }(\mathrm{MPa}) \text { blends with UV } \\
\text { stabilizers and Antioxidant }\end{array}$} \\
\hline & & \multicolumn{4}{|c|}{ Sample designation } \\
\hline & & $P A$ & $P B$ & $P C$ & $P D$ \\
\hline 1 & 0 & 2.74 & 2.79 & 2.78 & 2.82 \\
\hline 2 & 1167 & 1.63 & 1.62 & 2.01 & 1.50 \\
\hline 3 & 2333 & 1.42 & 1.44 & 1.89 & 1.49 \\
\hline 4 & 3500 & 1.51 & 1.54 & 1.93 & 1.47 \\
\hline
\end{tabular}

The Fig.13 shows the overall trend of Impact Test with radiant exposure of PMMA material

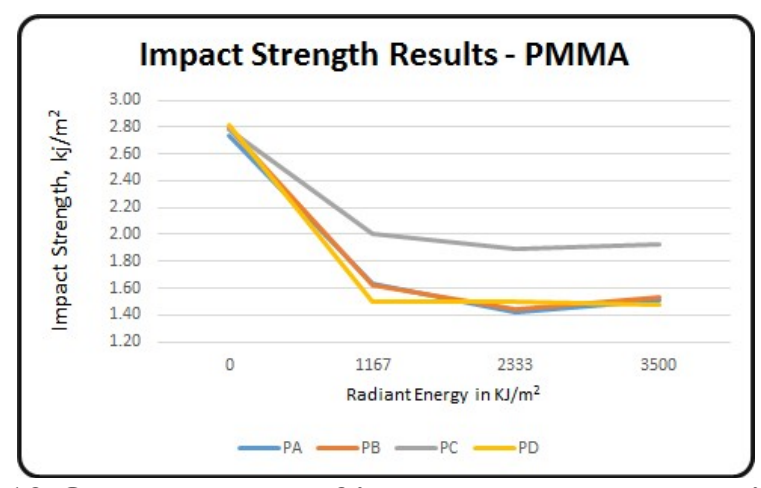

Fig.13 Overall trend of impact strength proprieties with radiant exposure of PMMA material
The results shows that Impact strength of PMMA samples PA, PB, PC and PD starts decreases continuously for the exposure of $3500 \mathrm{~kJ} / \mathrm{m}^{2}$. The variation was observed for the PMMA samples PA, $\mathrm{PB}, \mathrm{PC}$ and PD are $45.04 \%, 44.87 \%, 30.6 \%$ and $47.74 \%$ respectively. The sample PA which is a fresh sample without any concentration of UV and antioxidant shows the maximum percentage of Impact strength decline as compared to with bends of UV and antioxidants. However the sample AC shows the less decline of Impact strength in the order of $30.6 \%$ as compared to other samples. This trend shows that the concentration of $0.6 \%$ blends with UV stabilizers and $0.2 \%$ of Antioxidant shows the better results for the Impact strength of PMMA as compared to other percentage of blends concentration.

\subsection{Determination of Hardness D Test Results of PMMA}

Hardness D retention during weathering was studied for the specimens PA, PB, PC and PD. Table 9 shows the average Hardness strength retention test results of five PMMA polymer blend samples after intervals of $0 \mathrm{~h}, 1167 \mathrm{~kJ} / \mathrm{m}^{2}(865 \mathrm{~h}), 2333 \mathrm{~kJ} / \mathrm{m}^{2}(1730 \mathrm{~h})$, and $3500 \mathrm{~kJ} / \mathrm{m}^{2}(2596 \mathrm{~h})$ radiant exposure to weathering.

Table 9. Overall Hardness D Test Results after each radiant exposure of the PMMA bend samples

\begin{tabular}{|c|c|c|c|c|c|}
\hline \multirow[t]{3}{*}{$\begin{array}{l}\text { Sample } \\
\text { set No. }\end{array}$} & \multirow{3}{*}{$\begin{array}{c}\text { Total } \\
\text { radiant } \\
\text { energy } \\
\mathrm{kJ} / \mathrm{m} 2\end{array}$} & \multicolumn{4}{|c|}{$\begin{array}{l}\text { Average Tensile strength for } \\
\text { five sample (MPa) blends with } \\
\text { UV stabilizers and Antioxidant }\end{array}$} \\
\hline & & 7 & $\mathrm{npl}$ & signatic & \\
\hline & & $P A$ & $P B$ & $P C$ & $P D$ \\
\hline 1 & 0 & 82.20 & 80.40 & 83.00 & 80.60 \\
\hline 2 & 1167 & 83.80 & 84.20 & 83.00 & 83.00 \\
\hline 3 & 2333 & 85.60 & 86.00 & 82.80 & 85.00 \\
\hline 4 & 3500 & 88.60 & 87.80 & 86.40 & 87.20 \\
\hline
\end{tabular}

The Fig.14 shows the overall trend of Hardness Test with radiant exposure of PMMA material. 


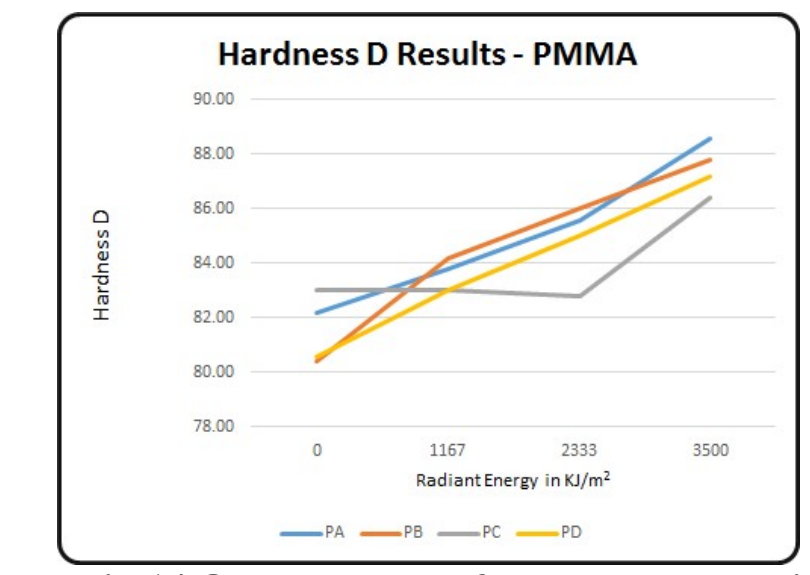

The Fig.14 Overall trend of Hardness Test with radiant exposure of PMMA material.

The results shows that Hardness D of PMMA samples PA, PB, PC and PD starts increases continuously for the exposure of $3500 \mathrm{~kJ} / \mathrm{m}^{2}$. The variation was observed for the PMMA samples PA, PB, PC and PD are $7.79 \%, 9.20 \%, 4.10 \%$ and $8.19 \%$ respectively. The sample PA which is a fresh sample without any concentration of UV, HALS and antioxidant shows the maximum percentage of Hardness D which is slightly higher as compared to with bends of UV and antioxidants. However the sample PC shows the less variation of Hardness D in the order of $4.10 \%$ as compared to other samples, however this also very close to the other samples. This trend shows that the concentration of $0.6 \%$ blends with UV stabilizers and $0.2 \%$ of Antioxidant shows the slightly better results for the Hardness D of PMMA as compared to other percentage of blends concentration.

\subsection{CONCLUSIONS}

When PMMA polymers are subjected to weathering, they are prone to underperform. Therefore to improve their properties over time, different kinds of additives such as UV stabilizers and Antioxidant are used. The stabilizers are designed to either inhibit or delay degradative changes rather than to stabilize properties. Different UV stabilizers and antioxidant in the range of $0.2 \%-1.0 \%$ and $0.2 \%$ respectively are used for intended functional life and sensitivity to UV degradation.

In this study, the comprehensive investigation was carried out to find out the mechanical properties behavior of PMMA with different percentages of UV stabilizers and Antioxidant by conducing Tensile Test, Flexural Test, Impact Test, Elongation Test, and Hardness Test as per the respective ASTM standards after different stages of $1167 \mathrm{~kJ} / \mathrm{m}^{2}(865 \mathrm{~h}), 2333$
$\mathrm{kJ} / \mathrm{m}^{2}(1730 \mathrm{~h})$, and $3500 \mathrm{~kJ} / \mathrm{m}^{2}(2596 \mathrm{~h})$ exposure of weathering.

Test results of mechanical test such as Tensile, Elongation, flexural, Impact and hardness of PMMA material after exposure of $0 \mathrm{~h}, 1167 \mathrm{~kJ} / \mathrm{m}^{2}(865 \mathrm{~h})$, $2333 \mathrm{~kJ} / \mathrm{m}^{2}(1730 \mathrm{~h})$, and $3500 \mathrm{~kJ} / \mathrm{m}^{2}(2596 \mathrm{~h})$ weathering in $\mathrm{Ci} 4000$ weather-ometer is as follows;

\subsubsection{Tensile Test:}

$>$ The tensile strength of PMMA samples of fresh, $0.2 \% \& 1.0 \%$ of UV stabilizers and $0.2 \%$ antioxidant starts decreases after continuously of weathering in the order of $8.8 \%$ to $26.3 \%$.

However the PMMA sample with $0.6 \%$ of UV stabilizers and $0.2 \%$ antioxidant blend shows the reasonably fewer decrease of tensile strength in the order of $8.8 \%$ only.

Experimental results shows that PMMA with $0.6 \%$ of UV stabilizers and $0.2 \%$ antioxidant blend gives the better tensile strength performance as compared to other percentage of blends.

\subsubsection{Elongation Test}

The Elongation test of PMMA samples of fresh, $0.2 \% \& 1.0 \%$ of UV stabilizers and $0.2 \%$ antioxidant starts decreases after continuously of weathering in the order of $14.0 \%$ to $54.0 \%$.

However the PMMA sample with $0.6 \%$ of UV stabilizers and $0.2 \%$ antioxidant blend shows the reasonable decrease of Flexural Strength in the order of 14.0 only.

Experimental results shows that PMMA with $0.6 \%$ of UV stabilizers and $0.2 \%$ antioxidant blend have a better retention of Flexural Strength as compared to other percentage of blends.

\subsubsection{Flexural Strength Test}

The Flexural Strength of PMMA samples of fresh, $0.2 \% \& 1.0 \%$ of UV stabilizers and $0.2 \%$ antioxidant starts decreases after continuously of weathering in the order of $2.5 \%$ to $12.54 \%$.

$>$ However the PMMA sample with $0.3 \%$ of UV stabilizers and $0.2 \%$ antioxidant blend shows the very insignificant decrease of Flexural Strength in the order of $2.5 \%$ only.

Experimental results shows that PMMA with $0.6 \%$ of UV stabilizers and $0.2 \%$ antioxidant blend have a better retention of Flexural Strength as compared to other percentage of blends. 


\subsubsection{Impact Strength Test}

$>$ The Impact Strength of PMMA samples of fresh, $0.2 \% \& 1.0 \%$ of UV stabilizers and $0.2 \%$ antioxidant starts decreases continuously of weathering in the order of $30.6 \%$ to $45.04 \%$.

$>$ However the PMMA sample with $0.6 \%$ of UV stabilizers and $0.2 \%$ antioxidant blend shows the decrease of Impact Strength in the order of $30.60 \%$.

$>$ Experimental results shows that PMMA with $0.6 \%$ of UV stabilizers and $0.2 \%$ antioxidant blend have a better retention of Impact Strength as compared to other percentage of blends.

\subsubsection{Hardness D Test}

> The Hardness D properties of PMMA samples of fresh, $0.2 \% \& 1.0 \%$ of UV stabilizers and $0.2 \%$ antioxidant starts decreases continuously of weathering in the order of $4.1 \%$ to $9.2 \%$.

$>$ However the PMMA sample with $0.6 \%$ of UV stabilizers and $0.2 \%$ antioxidant blend shows the decrease of Hardness D properties in the order of $4.2 \%$.

\begin{tabular}{|c|c|c|c|}
\hline $\begin{array}{l}\text { Sr. } \\
\text { No. }\end{array}$ & Name of Components & Type & $\%$ wt \\
\hline 1 & Polymer (thermoplastic) & $\begin{array}{l}\text { Poly(methyl methacrylate) (PMMA) } \\
\left(\underline{\mathrm{C}}_{5} \underline{\mathrm{O}}_{2} \underline{\mathrm{H}}_{8}\right)_{n}\end{array}$ & $99.2 \%$ \\
\hline 2 & $\begin{array}{l}\text { Benzoxazinone based } \\
\text { UV light stabilizer }\end{array}$ & $\begin{array}{l}\text { UV531 } \\
\text { [2-hydroxy-4-octyloxybenzophenone] }\end{array}$ & $0.3 \%$ \\
\hline 3 & $\begin{array}{l}\text { Diphenyl acrylates based } \\
\text { UV light stabilizer }\end{array}$ & $\begin{array}{l}\text { UV335 } \\
\text { [ethyl-2-cyano-3,3-diphenylacrylate] }\end{array}$ & $0.3 \%$ \\
\hline 4 & $\begin{array}{lr}\text { Antioxidant } & \text { primary } \\
\text { Antioxidant } & \text { secondary } \\
\text { (Mixture of 3:1 ratio) }\end{array}$ & $\begin{array}{l}\text { Primary Antioxidant } 1010 \text { [Tetrakis } \\
\text { [methylene- } \beta-(3,5 \text {-di-tert-butyl-4- } \\
\text { hydroxyphenyl)-propionate]methane] } \\
\text { S Secondary Antioxidant } 168 \text { [Tris(2,4-ditert- } \\
\text { butylphenyl)phosphite] }\end{array}$ & $0.2 \%$ \\
\hline
\end{tabular}

Study shows that improved mechanical properties of PMMA with the above compounding material can further enhance the performance of safety critical components used of vehicles

> Comprehensive study results available for manufacturer to select different UV light stabilizers and Antioxidant compounding PMMA material as per the usage and application.
Experimental results shows that PMMA with $0.6 \%$ of UV stabilizers and $0.2 \%$ antioxidant blend have a better retention of Hardness D properties as compared to other percentage of blends.

\subsection{Conclusion}

The investigation shows that significant changes observed in the mechanical properties of fresh (without any UV and antioxidant) PMMA after conducing Tensile Test, Flexural Test, Impact Test, Elongation Test, and Hardness Test as per the respective ASTM standards after different stages of $875 \mathrm{~kJ} / \mathrm{m}^{2}, 1750 \mathrm{~kJ} / \mathrm{m}^{2}, 2625 \mathrm{~kJ} / \mathrm{m}^{2}$ and $3500 \mathrm{~kJ} / \mathrm{m}^{2}$ laboratory weathering.

Experimental results shows that PMMA with $0.6 \%$ of UV stabilizers and $0.2 \%$ antioxidant blend have a better retention of for all mechanical properties as compared to other percentage of blends. . The following percentage of blends are recommended for PMMA to retain mechanical properties for the weathering. 
International Journal of Trend in Scientific Research and Development (IJTSRD) ISSN: 2456-6470

3. "Weathering Testing Guidebook" by Atlas Material Testing Solutions, 2001 Atlas Electric Devices Company USA.

4. "Material weathering" Hand book $5^{\text {th }}$ sedition by George Wypych William Andrew publishing ISBN 1-895198-28-3.

5. "Plastics design" Hand Book $3^{\text {rd }}$ edition by Plastics design handbook by Dominick V. Rosato, Donald V. Rosato, Marlene G. Rosato. ISBN 978-0-7923-7980-5

6. "Rubber Hand book" $4^{\text {th }}$ sedition by Vanderbilt ISBN-10: 9990566348

7. SAE technical paper No.:2003-01-1192 titled "Highly Predictive Accelerated Weathering of Engineering Thermoplastics by James E. Pickett GE Global Research SV. Umamaheswaran GE Plastics - 5

8. SAE technical paper No.:2003-01-1195 titled "Development of a Carbon/Epoxy Body for a High Performance Vehicle

9. SAE technical paper No.:2003-01-1191 titled "Weathering of Black Plastics for Automotive Exteriors

10. Journal titled "Influence of UV absorber on photodegradation processes of poly(vinyl chloride) with different average degrees of polymerization" by Society of Plastics Engineers POLYM. ENG. SCI., 47:14801490, 2007,

11. Journal titled "Photostabilizing efficiency of ultraviolet light stabilizers for rigid poly(vinyl chloride) against photo-oxidation" Society of Plastics Engineers POLYM. ENG. SCI., 2013

12. Journal titled titled "Effect of stabilizer type on artificial weathering of rigid PVC. $\mathrm{II}^{\dagger}$ " Society of Plastics Engineers POLYM. ENG. SCI., 2013

13. Journal titled "Thermal and photo-degradation of unstabilized ABS" by J.B.Adeniyi and E.G.Kolawole, Department of Chemistry, Ahmadu Bello University, Zaria, Nigeria

14. Journal titled Degradation of acrylonitrilebutadiene-styrene and polycarbonate by UV irradiation by R. Ramani a, C. Ranganathaiah, Polymer Degradation and Stability 69 (2000) $347 \pm 354$
15. Boldizar, A \& Moller, K 2003, 'Degradation of ABS during repeated processing and accelerated ageing', Polymer Degradation and Stability, vol. 81, no. 2, pp. 359-366

16. Atlas of polymer and plastics analysis - Vol. 3 Additives and processing Aids by carl Hanser Verlag, ISBN No.30446-12592-2

17. Patented No. WO 2007083290 A2 by Reuven Hugi and Haim Geva titled "Ultraviolet protected polyethersulfones"

18. Patent No.: US $6,843,939$ B2 by Stretanski etal. Titled "UV stabilizing additive composition".

19. Journal titled "Finescale Diurnal Rainfall Statistics Refined from Eight Years of TRMM PR Data" MASAFUMI HIROSE, etl. Earth Observation Research Center, Japan Aerospace Exploration Agency, Tsukuba, Japan

20. Journal titled "Thailand Daily Rainfall and Comparison with TRMM Products" ROONGROJ CHOKNGAMWONG, Center for Earth Observing and Space Research, George Mason University, Fairfax, Virginia

21. alIS-15223-interiorfittingsAutomotive vehicles - interior Fittings - specification

22. IS-11939-steeringimpactAutomotive vehiclessteering Control systems- impact Protection requirements and Methods of measurement

23. AIS:006 Automotive Vehicles - Bumper fitment on M1 Category of Vehicles - Test Methods

24. AIS:012 Requirements of Light and signaling devices for four wheeled vehicles

25. AIS:010 Requirements of Light and signaling devices for two and thee wheeled vehicles

26. AIS:062 Requirements of Light and signaling devices for tractors

27. ECE R 112 Uniform provisions concerning the approval of motor vehicle headlamps emitting an asymmetrical passing beam or a driving beam or both and equipped with filament lamps

28. ECE R 113 Uniform provisions concerning the approval of motor vehicle headlamps emitting an symmetrical passing beam or a driving 
International Journal of Trend in Scientific Research and Development (IJTSRD) ISSN: 2456-6470

beam or both and equipped with filament lamps

29. ECE R 27 Uniform provisions concerning the approval of advance warning triangle

30. ECE R 104 Uniform provisions concerning the approval of retro-reflective markings for heavy and long vehicles and their trailers

31. ISO 5740 - 1982 : "Road vehicles - Rear view mirrors - Test for determining reflectance".

32. ISO 4892-1,2,3,4 Plastics and varnishes Method of exposure to laboratory light sources- Part 1: General guidance, Part 2 : Xenon arc sources

33. ISO: 105 Textiles - tests for colorfastness Part B02: Colorfastness to Weathering Xenon Arc.

34. SAE J 1960 Accelerated Exposure of Automotive Exterior Materials Using a Controlled Irradiance Water-cooled Xenon Arc Apparatus

35. SAE J 1545 specifies the procedures for instrumental color difference measurement of colored parts or colored

36. ASTM G 26 Standard practice for operating Light - Exposure Apparatus (Xenon Arc Type) with and without water for exposure of nonmetallic materials.

37. ASTM D 256 : "Standard Test Methods for Determining the Izod Pendulum Impact Resistance of Plastics"

38. ASTM D 638 : "Standard Test Method for Tensile Properties of Plastics"

39. ASTM D 790 : "Standard Test Methods for Impact Properties of Unreinforced and Reinforced Plastics and Electrical Insulating Materials"
40. ASTM D 2240 : "Standard Test Method for Rubber Property_ D Durometer Hardness"

\section{Appendix A}

\section{Irradiance Exposure calculation}

The average total $(295-3000 \mathrm{~nm})$ irradiance per year is $6966 \mathrm{MJ} / \mathrm{m}^{2}$, which is equal to around $3500 \mathrm{~kJ} / \mathrm{m}^{2}$ for $0.55 \mathrm{~W} / \mathrm{m}^{2}$ at $340 \mathrm{~nm}$.

The sample calculation for exposure is as follows [3];

$>$ Radiant exposure is irradiance integrated over time. Therefore, the following equation applies: $\mathrm{W} / \mathrm{m}^{2} \cdot$ time (seconds) $=\mathrm{J} / \mathrm{m} 2$

In a Weather-Ometer radiant exposure is normally measured in $\mathrm{kJ} / \mathrm{m} 2$, so joules $(\mathrm{J})$ must be converted to kilojoules $(\mathrm{kJ}): 1 \mathrm{~J} / \mathrm{m} 2=$ $0.001 \mathrm{~kJ} / \mathrm{m} 2$

Artificial weathering tests are timed in hours: 3600 seconds $=1$ hour

All of these conversions can be combined to obtain the following equation:

$\mathrm{kJ} / \mathrm{m} 2=\mathrm{W} / \mathrm{m} 2 \times 3.6 \times$ hours

The total energy $=6966 \mathrm{MJ} / \mathrm{m} 2=6966000 \mathrm{kj} / \mathrm{m} 2$ for global radiation

The set irradiance at equipment is $0.55 \mathrm{~W} / \mathrm{m}^{2} 340 \mathrm{~nm}$ equals about $1120 \mathrm{~W} / \mathrm{m}^{2}$ global irradiance (equipment specification defined by manufacturer) $6966000 \mathrm{~kJ} / \mathrm{m}^{2}$ $/\left(1120 \mathrm{~W} / \mathrm{m}^{2} \mathrm{X} 3.6 \mathrm{~h}\right)=1730$ hours

Radiation is only collected during light-hours of the test method. But for test method SAE J1960 which has a 2 hour light period followed by 1 hour dark this means, total test time $(1730 / 2) \times 3=2596$ hours. Hence, the average total $(295-3000 \mathrm{~nm})$ irradiance per year is $6966 \mathrm{MJ} / \mathrm{m}^{2}$, which is equal to around $3500 \mathrm{~kJ} / \mathrm{m}^{2}$ for $0.55 \mathrm{~W} / \mathrm{m}^{2}$ at $340 \mathrm{~nm}$.

The tests are conducted at the intervals of 875 $\mathrm{kJ} / \mathrm{m}^{2}$ (649 h), $1167 \mathrm{~kJ} / \mathrm{m}^{2}(1298 \mathrm{~h}), 2334 \mathrm{~kJ} / \mathrm{m}^{2}$ (1947 h) and $3500 \mathrm{~kJ} / \mathrm{m}^{2}(2596 \mathrm{~h})$ exposure of weathering. 